\title{
(- OPEN ACCESS \\ Mortality inequalities by occupational class among men in Japan, South Korea and eight European countries: a national register-based study, 1990-2015
}

\author{
Hirokazu Tanaka, ${ }^{\oplus 1,2}$ Wilma J Nusselder, ${ }^{1}$ Matthias Bopp, ${ }^{03}$ \\ Henrik Brønnum-Hansen, ${ }^{\oplus}$ Ramune Kalediene, ${ }^{\oplus 5}$ Jung Su Lee, ${ }^{2}$ Mall Leinsalu, ${ }^{\oplus 6,7}$ \\ Pekka Martikainen, ${ }^{\oplus 8}$ Gwenn Menvielle, $^{\oplus 9}{ }^{9}$ asuki Kobayashi, ${ }^{2}$ Johan P Mackenbach ${ }^{1}$
}

\begin{abstract}
- Additional material is published online only. To view please visit the journal online (http://dx.doi.org/10. 1136jech-2018-211715).
\end{abstract}

For numbered affiliations see end of article.

\section{Correspondence to} Johan P Mackenbach, Department of Public Health, Erasmus University Medical Center, P.O. Box 2040, 3000 CA Rotterdam, The Netherlands; j. mackenbach@erasmusmc.nl

Received 9 October 2018 Revised 1 March 2019 Accepted 1 May 2019 Published Online First 29 May 2019

\begin{abstract}
Background We compared mortality inequalities by occupational class in Japan and South Korea with those in European countries, in order to determine whether patterns are similar.

Methods National register-based data from Japan, South Korea and eight European countries (Finland, Denmark, England/Wales, France, Switzerland, Italy (Turin), Estonia, Lithuania) covering the period between 1990 and 2015 were collected and harmonised. We calculated age-standardised all-cause and cause-specific mortality among men aged 35-64 by occupational class and measured the magnitude of inequality with rate differences, rate ratios and the average inter-group difference.

Results Clear gradients in mortality were found in all European countries throughout the study period: manual workers had 1.6-2.5 times higher mortality than upper non-manual workers. However, in the most recent time-period, upper non-manual workers had higher mortality than manual workers in Japan and South Korea. This pattern emerged as a result of a rise in mortality among the upper non-manual group in Japan during the late 1990s, and in South Korea during the late 2000 s, due to rising mortality from cancer and external causes (including suicide), in addition to strong mortality declines among lower non-manual and manual workers. Conclusion Patterns of mortality by occupational class are remarkably different between European countries and Japan and South Korea. The recently observed patterns in the latter two countries may be related to a larger impact on the higher occupational classes of the economic crisis of the late 1990s and the late 2000s, respectively, and show that a high socioeconomic position does not guarantee better health.
\end{abstract}

\section{INTRODUCTION}

Health inequalities between socioeconomic groups remain an important challenge for health and social policy around the world. ${ }^{1}$ Health inequalities are usually observed as a gradient, that is, a gradual, stepwise increase of morbidity and mortality among people lower on the social ladder. ${ }^{2}$ This suggests that the causes of inequalities in health are not simply poverty, or other unfavourable circumstances at the extremes of the social ladder, but factors that operate for everyone in society, such as psychosocial stress or social comparisons. ${ }^{3}$
Due to favourable behaviour changes and advances in prevention and treatment over the last 50 years, Japan and South Korea, the Asian member countries of the Organisation for Economic Cooperation and Development (OECD), have very long life expectancy. Thus, both countries have been recognised as global life expectancy leaders, together with European countries such as Switzerland, France, Spain and Italy. ${ }^{4}$ Although population health in Japan and South Korea shares many features with Western European countries, health inequalities in Japan and South Korea have sometimes been reported to be unique, ${ }^{6-9}$ with the highest socioeconomic groups not always having the best health, whereas in European countries inequalities in mortality and morbidity by socioeconomic position usually form steep and persistent gradients. ${ }^{10-12}$ Trend studies from Japan and South Korea have also shown remarkable trends, with rising all-cause mortality among managers and professionals after the late 1990s in Japan, ${ }^{13} 14$ and rising suicide mortality among managers after the late 2000s in South Korea. ${ }^{15}$

While some studies thus suggest that Japan and South Korea have unique patterns and trends of health inequalities, due to a lack of direct comparisons to other high-income countries this has remained uncertain. ${ }^{69}$ This study therefore aimed to systematically compare the magnitude and pattern of mortality inequalities by occupational class in Japan and South Korea with those in European OECD countries over the past 25 years. Documenting similarities and differences between two world regions will not only help to complete the global picture of health inequalities, but may also help to raise new hypotheses about the root causes of this phenomenon.

\section{METHODS}

\section{Data sources}

We analysed national register-based data from eight European countries (Finland, Denmark, England/ Wales, France, Switzerland, Italy (Turin), Estonia, Lithuania), Japan and South Korea. Our research group has collected mortality data by education and occupational class for a wide range of European countries, ${ }^{10-12}$ and the present study includes all European countries for which detailed mortality data by occupational class are available. Although mortality data for Italy came from Turin, an urban 
population in Northern Italy, previous studies have shown that patterns observed in Turin are similar to those observed at the national level. ${ }^{16} 17$

For European countries, information on occupational class for both the population denominator and the deceased were reported in the census. ${ }^{10-12}$ For Japan and South Korea, information on occupational class for the population denominator came from the census and that for the deceased was reported by the family on the death certificates. ${ }^{14}{ }^{18}$ We used mortality data observed over 25 years divided into six periods: 1990 1994, 1995-1999, 2000-2004, 2005-2009, 2010-2014 and 2015 (the latter available for Japan and South Korea only) or similar. Underlying causes of death were classified according to the International Statistical Classification of Diseases (ICD, various revisions) and grouped into four broad groups (cancers, cardiovascular diseases, all other diseases and external causes), and eight specific causes of death known to be highly prevalent in Japan and South Korea. An overview of the data is presented in online supplementary appendix 1.

\section{Occupational class}

We categorised occupational class into five categories: upper non-manual workers (eg, professionals, managers), lower non-manual workers (eg, clerical, service, sales workers), manual workers (eg, craft and related trades workers, semi-skilled and unskilled manual workers), farmers and self-employed. This classification followed the Erikson-Goldthorpe-Portocarero scheme which was developed for international comparisons. ${ }^{19}$ The classification of specific occupations by occupational class is presented in online supplementary appendix 2, which also presents the educational composition of each occupational class in all countries included in the study except France. Online supplementary appendix table 2-1 presents the occupational class classification in Japan and South Korea; cross-national comparisons between European countries and East Asian countries have shown that despite some differences the patterns of social stratification and social mobility are largely similar. ${ }^{20} 21$ Because reliable occupational class data were not available for women and older men, the analyses will be restricted to men aged 35-64 years.

\section{Analysis}

Age-standardised mortality rates (ASMR) by occupational class were computed using the 2013 European standard population and data in 5 year age intervals. In all countries except Finland, England/Wales and Italy (Turin), the last occupation was unknown for economically inactive men. This may cause bias, because economically inactive men tend to have higher mortality than economically active men, and because men in lower occupational classes have a higher likelihood of being economically inactive. For these countries, we therefore applied a previously developed and validated correction procedure (online supplementary appendix 3). ${ }^{22-24}$ Online supplementary appendix table 3-2 shows the percentages of men for whom occupational class was unknown in our dataset.

To measure inequality in mortality we computed rate differences (RDs) and rate ratios (RRs) by occupational class using upper non-manual workers as reference group. RDs were directly calculated as differences between the ASMRs of occupational classes. RRs adjusted for age and 95\% CIs were estimated with Poisson regression. We also computed average inter-group differences (AIDs) as a summary measure of mortality inequality taking into account all occupational classes and their relative sizes. ${ }^{25}$ The AID has also been referred to as the 'index of dissimilarity', 'index of disparity' and 'dispersion measure of mortality'. ${ }^{26-28}$ The AID (absolute version) was computed as the population weighted average of mortality differences within all pairs of occupational classes. For groups $i$ and $j$ (here, occupational class), the formula for the AID (absolute version) is:

$$
\begin{aligned}
\operatorname{AID}_{t} \text { (absolute version) }= & \frac{1}{2} \sum_{i=1}^{N} \sum_{j=1}^{N} \\
& \left|\operatorname{ASMR}_{t, i}-\operatorname{ASMR}_{t, j}\right| p_{t, i} p_{t, j}
\end{aligned}
$$

where $p_{t, i}$ and $p_{t, j}$ are the population shares of occupational class $i$ and $j$ in the total population $(i, j=1,2, \ldots, N)$ at time $t$. In our analysis, $N=5$ (five occupational classes: upper non-manual, lower non-manual, manual workers, self-employed and farmers (four classes in some countries)). The AID (relative version) was computed as the AID (absolute version) divided by the average mortality rate in the whole male population aged 35-64 years. The AID (relative version) multiplied by 100 equals to the Gini coefficient which is often used as a measure of economic inequality in a population. ${ }^{29}$ The formula for the AID (relative version) is:

$$
\left.\operatorname{AID}_{t} \text { (relative version }\right)(\%)=\frac{\operatorname{AID}_{t} \text { (absolute version) }}{\mathrm{ASMR}_{t} \text { (whole population) }} \times 100
$$

The AID can be interpreted as the number or proportion of deaths that would have to be redistributed between occupational classes to achieve perfect equality. ${ }^{26}$

\section{RESULTS}

\section{Mortality inequality by occupational class}

We observed a total of 1570708 deaths occurring in 293370 858 person-years in Japan, South Korea and eight European countries combined over the whole study period between 1990 and 2015.

Figure 1 presents the ASMRs among men aged 35-64 by occupational class during the most recent period, with the height of bars indicating the mortality rate and the width of bars indicating the share of each occupational class in the population (online supplementary appendix table 4-1 to 4-10). The mortality rates in Japan and South Korea were comparatively low as they were in England/Wales, Switzerland and Italy (Turin), whereas they were very high in Estonia and Lithuania. Manual workers accounted for the largest percentages of population except in England/Wales, France and Switzerland where the upper non-manual workers were the largest group. The social gradient was clear and consistent in all European countries; that is, upper non-manual workers had the lowest mortality and manual workers had the highest mortality, with farmers and self-employed often having lower mortality than manual workers. However, the social gradient was different in Japan and South Korea; that is, farmers and upper non-manual workers had the highest and second highest mortality, respectively, whereas lower non-manual (Japan) and manual workers (South Korea) had the lowest mortality.

Table 1 shows absolute and relative inequalities in all-cause mortality as measured by RDs and RRs with upper non-manual workers as reference group in an earlier and in the most recent period. The RDs for manual workers have decreased in most European countries with the exception of Lithuania, whereas the RRs have sometimes decreased, and sometimes increased. However, in both Japan and South Korea the mortality disadvantage of manual workers has reversed into a mortality advantage: in Japan, the RR for manual workers changed from 1.13 (95\% CI 1.10 to 1.15 ) in 1995 to 0.93 (95\% CI 0.90 to 0.96 ) in 2015, and in South Korea the RR for manual workers changed 


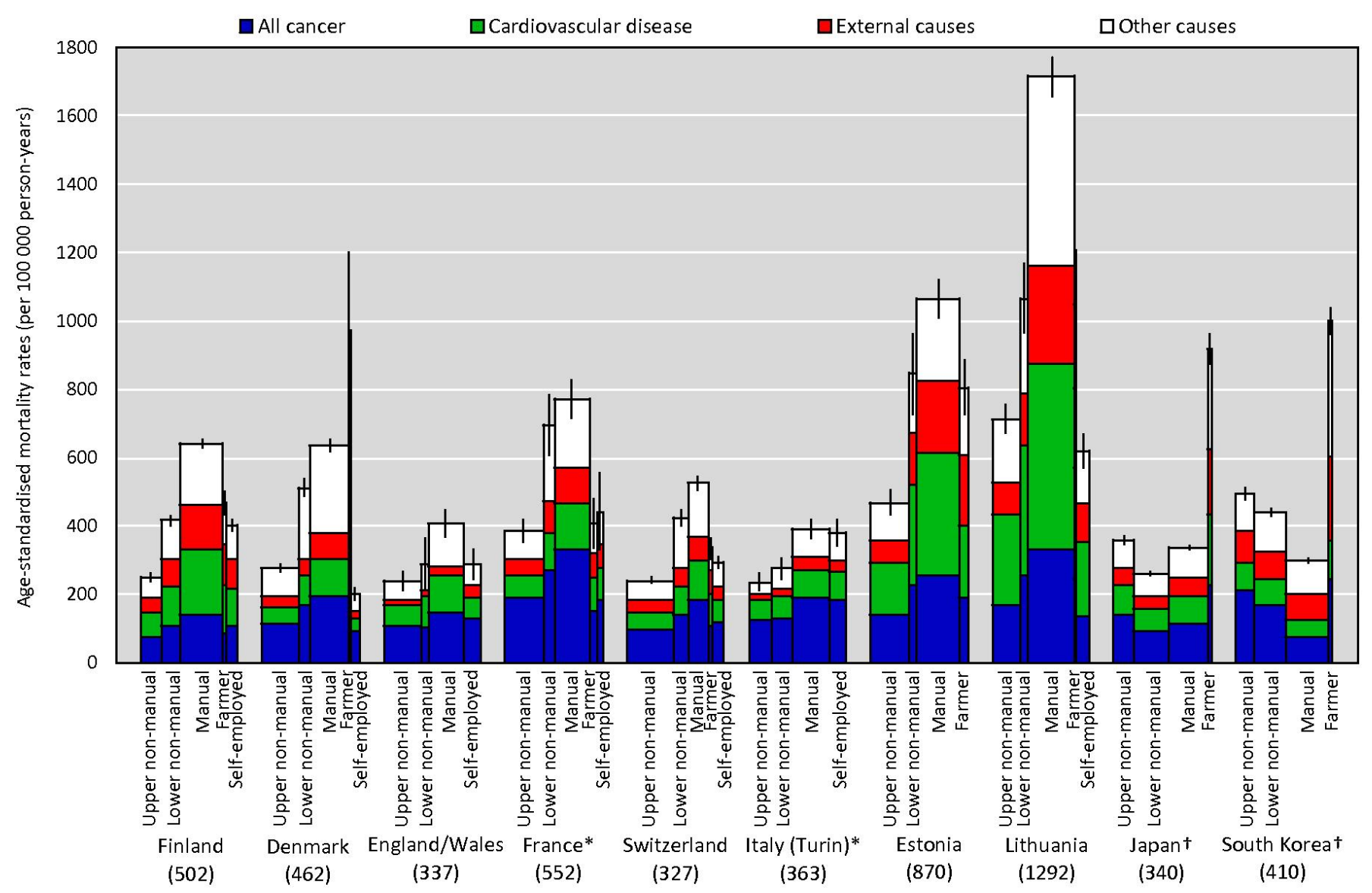

Figure 1 Age-standardised cause-specific mortality rate $(95 \% \mathrm{Cl})$ and population distribution by occupational class among men aged 35-64 in eight European countries, Japan and South Korea, 2010-2014 (2005-2009*, 2015t): number in parentheses indicate the whole population agestandardised all-cause mortality rate (per 100000 person-years).

from 2.48 (95\% CI 2.39 to 2.57 ) in 1997 to 0.63 (95\% CI 0.61 to 0.65 ) in 2015 .

In the most recent period, cancer was the most important contributor (about 30\%-35\%) to inequalities in all-cause mortality between manual and upper non-manual workers in France, Switzerland and Italy (Turin), while cardiovascular disease was the most important contributor (about 30\%-35\%) in Finland, England/Wales, Estonia and Lithuania. In Japan and South Korea, cancer was by far the most important contributor (about 50\%-80\%) (data shown in online supplementary appendix table 4-11).

\section{Trends in mortality by occupational class}

Figure 2 shows temporal trends in mortality by occupational class for upper non-manual, lower manual and manual workers. Mortality declined steadily in most European countries with the exception of Lithuania; however, in Japan and South Korea upper non-manual workers' mortality rose after 2000 and after 2010, respectively. We observed consistently low and decreasing mortality among manual workers in Japan and very large mortality declines among both lower non-manual and manual workers in South Korea. The recently observed mortality patterns in Japan emerged during the late 1990s, and those in South Korea emerged during the late 2000s (see also online supplementary appendix figures 4-1 and 4-2).

Table 2 shows changes in mortality by cause of death among upper non-manual workers in Japan and South Korea. The increase in mortality in Japan in 1995-2000 was almost twice as large as the increase in mortality in South Korea in 20052010: all-cause mortality increased by $57 \%$ in Japan and 35\% in South Korea. Many causes of death contributed to increasing mortality, but the largest percentage increases were seen for external causes $(+118 \%$ in Japan $(1995-2000)$ and $+51 \%$ in South Korea (2005-2010)), particularly for suicide $(+182 \%$ in Japan (1995-2000) and $+93 \%$ in South Korea (2005-2010)). In absolute terms, cancer made the largest contribution to rising all-cause mortality both in Japan and South Korea in this occupational class.

\section{Mortality inequality assessed by the AIDs}

Figure 3 shows absolute and relative inequalities in mortality as measured by AIDs (see also online Supplementary Appendix Figure 4-3). In 2010-2014 the largest relative AIDs (between $16 \%$ and 24\%) were found in Finland, Denmark, Switzerland, Estonia, Lithuania and South Korea, but inequalities in South Korea were declining steeply. Japan had comparatively small mortality inequalities both in absolute and relative terms except in 2000 and 2005. In all countries except Lithuania, absolute inequalities declined over time, whereas trends in relative inequalities showed a more variable pattern.

\section{DISCUSSION}

\section{Strengths and limitations}

To the best of our knowledge, this is the first study which directly compared nation-wide inequalities in mortality between European 
Table 1 Distribution of men (\%), age-standardised all-cause mortality rate difference (RD)* and rate ratio (RR) + with their $95 \%$ Cls by occupational classł

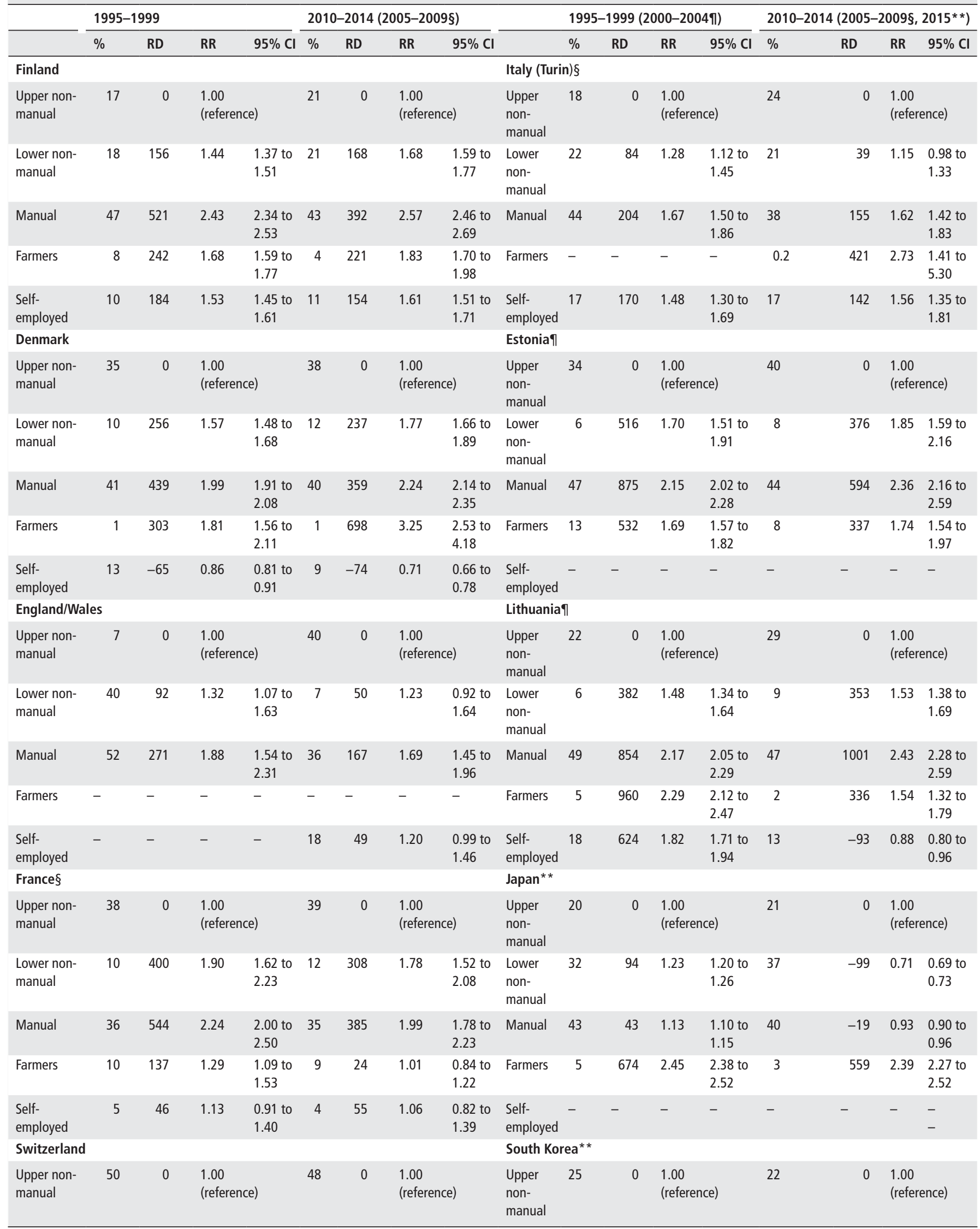


Table 1 Continued

\begin{tabular}{|c|c|c|c|c|c|c|c|c|c|c|c|c|c|c|c|c|c|}
\hline & \multicolumn{4}{|c|}{ 1995-1999 } & \multicolumn{4}{|c|}{ 2010-2014 (2005-2009§) } & & \multicolumn{4}{|c|}{ 1995-1999 (2000-2004ף) } & \multicolumn{4}{|c|}{ 2010-2014 (2005-2009§, 2015**) } \\
\hline & $\%$ & RD & $\mathbf{R R}$ & $95 \% \mathrm{Cl}$ & $\%$ & RD & $\mathbf{R R}$ & $95 \% \mathrm{Cl}$ & & $\%$ & RD & $\mathbf{R R}$ & $95 \% \mathrm{Cl}$ & $\%$ & RD & $\mathbf{R R}$ & $95 \% \mathrm{Cl}$ \\
\hline $\begin{array}{l}\text { Lower non- } \\
\text { manual }\end{array}$ & 16 & 242 & 1.63 & $\begin{array}{l}1.57 \text { to } \\
1.70\end{array}$ & 15 & 182 & 1.72 & $\begin{array}{l}1.62 \text { to } \\
1.83\end{array}$ & $\begin{array}{l}\text { Lower } \\
\text { non- } \\
\text { manual }\end{array}$ & 23 & 1022 & 3.80 & $\begin{array}{l}3.66 \text { to } \\
3.95\end{array}$ & 32 & -57 & 0.92 & $\begin{array}{l}0.89 \text { to } \\
0.95\end{array}$ \\
\hline Manual & 17 & 408 & 2.05 & $\begin{array}{l}1.98 \text { to } \\
2.13\end{array}$ & 20 & 284 & 2.17 & $\begin{array}{l}2.06 \text { to } \\
2.28\end{array}$ & Manual & 36 & 436 & 2.48 & $\begin{array}{l}2.39 \text { to } \\
2.57\end{array}$ & 44 & -199 & 0.63 & $\begin{array}{l}0.61 \text { to } \\
0.65\end{array}$ \\
\hline Farmers & 5 & 59 & 1.17 & $\begin{array}{l}1.10 \text { to } \\
1.24\end{array}$ & 4 & 95 & 1.40 & $\begin{array}{l}1.27 \text { to } \\
1.53\end{array}$ & Farmers & 15 & 1011 & 3.97 & $\begin{array}{l}3.82 \text { to } \\
4.12\end{array}$ & 4 & 502 & 1.96 & $\begin{array}{l}1.88 \text { to } \\
2.06\end{array}$ \\
\hline $\begin{array}{l}\text { Self- } \\
\text { employed }\end{array}$ & 13 & 105 & 1.27 & $\begin{array}{l}1.22 \text { to } \\
1.32\end{array}$ & 12 & 53 & 1.22 & $\begin{array}{l}1.15 \text { to } \\
1.30\end{array}$ & $\begin{array}{l}\text { Self- } \\
\text { employed }\end{array}$ & - & - & - & - & - & - & - & - \\
\hline
\end{tabular}

${ }^{*}$ RDs were calculated using direct method with the 2013 European standard population.

tRRs and $95 \%$ Cls were estimated with Poisson regression adjusting age.

$\ddagger$ Results were applied to correction factors by countries and periods.

§France and Italy (Turin) in 2005-2009.

IEstonia and Lithuania in 2000-2004.

**Japan and South Korea in 2015

countries, Japan and South Korea. Such a broad coverage, however, also increases the likelihood of comparability problems. Although we have carefully harmonised the data, some technical comparability problems remained. First, we were unable to distinguish the self-employed in Japan and South Korea (and in Estonia), because self-employment status was not registered on the death records. We therefore carried out a sensitivity analysis, using data on the proportion of self-employed by occupational class in Japan and South Korea from other sources, and the observed mortality rates

(A) Upper non-manual worker

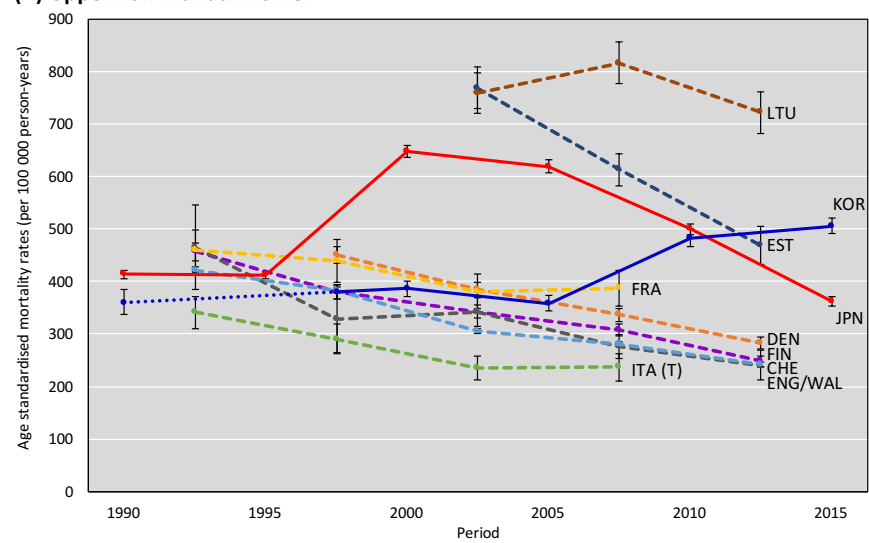

(C) Manual worker

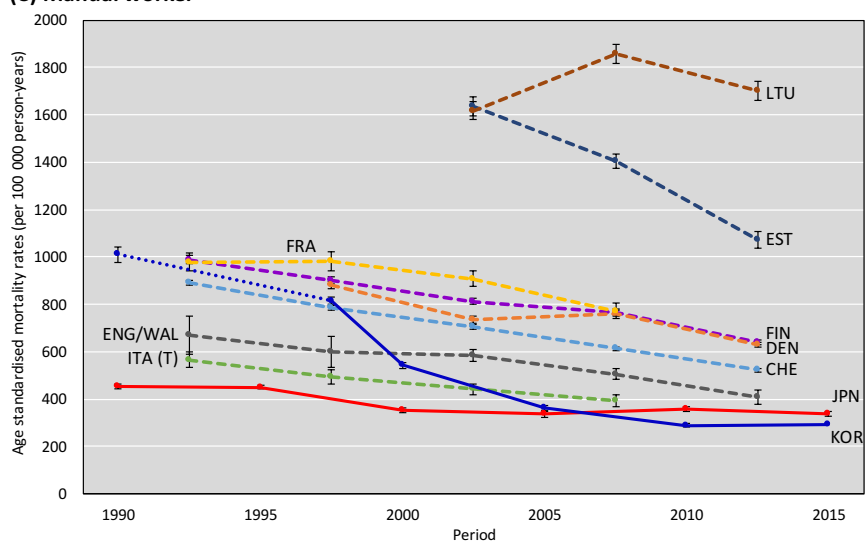

among the self-employed as compared with the whole population in European countries. Although the self-employed are a heterogeneous category which cannot be assumed to represent exactly the same social group in all countries, the results (shown in online supplementary appendix 5) show that the pattern of mortality inequalities by occupational class in Japan and South Korea, including the higher mortality rate of upper non-manual group, is unlikely to be explained by lack of data on mortality of the self-employed.

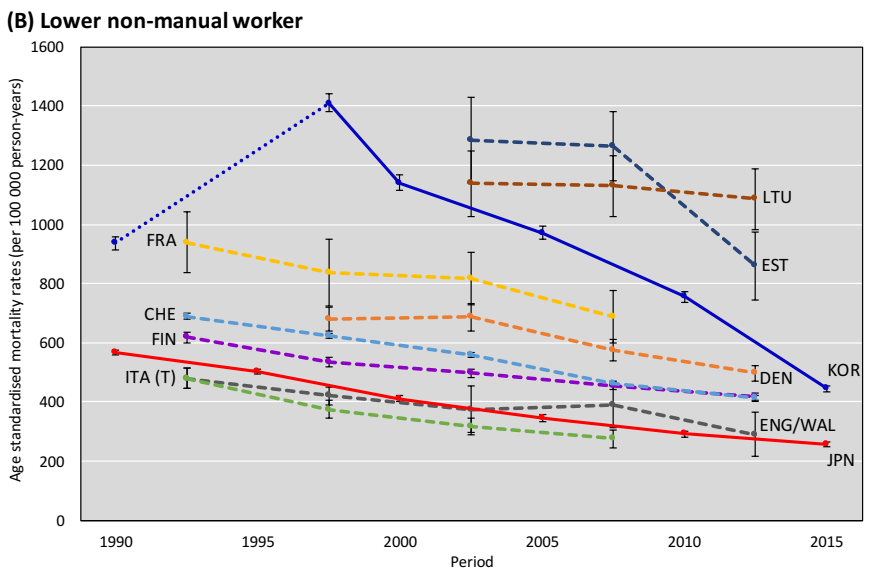

$$
\begin{aligned}
& \text { Legends }
\end{aligned}
$$

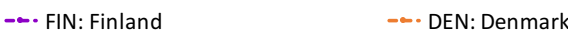

$$
\begin{aligned}
& \cdots \text { ENG/WAL: England/Wales } \quad \cdots \text { FRA: France } \\
& \text { - CHE: Switzerland … ITA (T): Italy (Turin) } \\
& \text { - EST: Estonia } \quad \cdots \text { LTU: Lithuania } \\
& \rightarrow \text { JPN: Japan } \rightarrow \text { KOR: South Korea }
\end{aligned}
$$

Figure 2 Trends in age-standardised all-cause mortality rates $(95 \% \mathrm{Cl})$ by occupational class (upper non-manual, lower manual and manual workers). 
Table 2 Changes in age-standardised all-cause and cause-specific mortality rate among upper non-manual workers in Japan and South Korea*

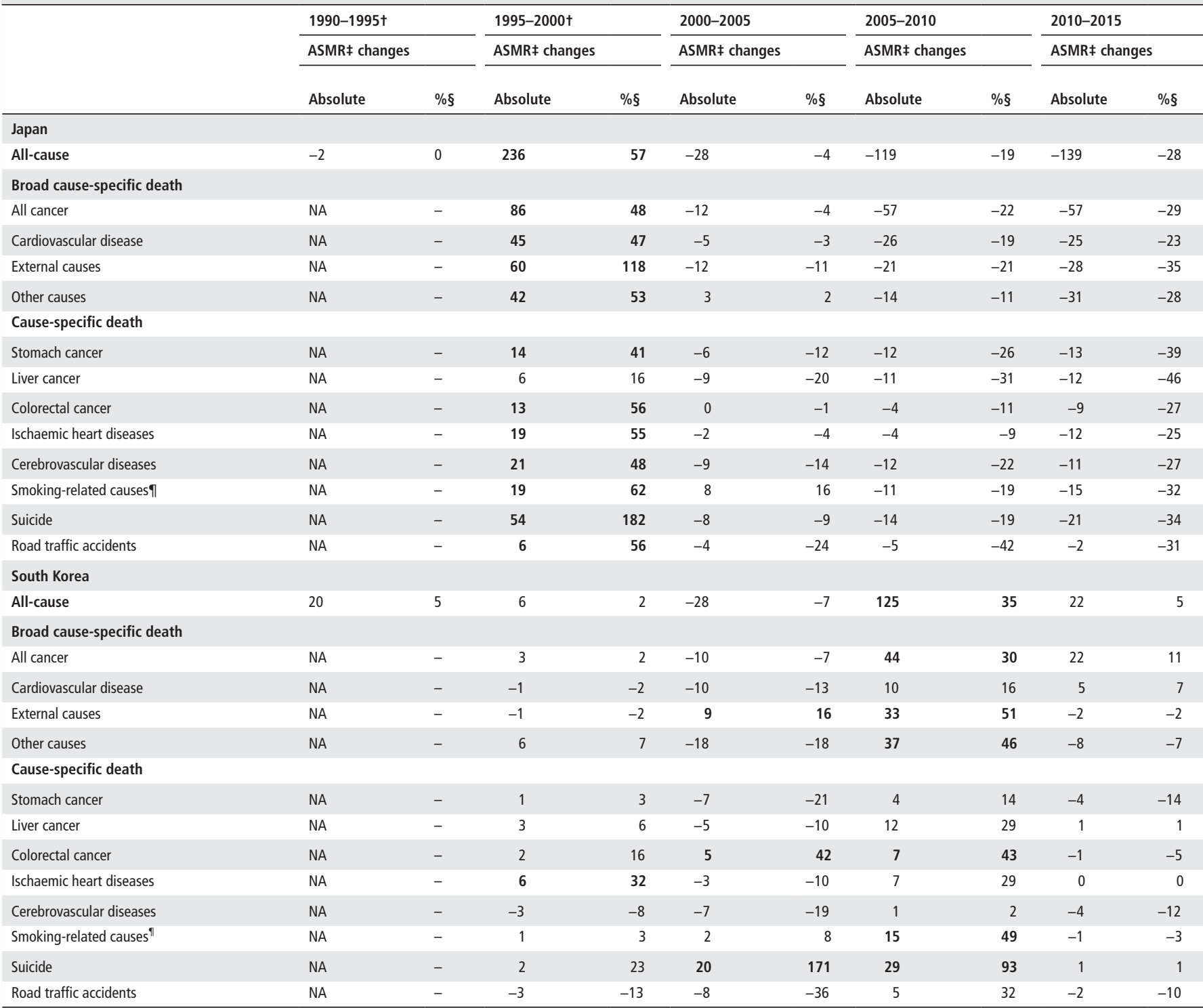

${ }^{*}$ The plus values (significant mortality increasing) were indicated by bold $(p<0.05)$

†1990-1997 and 1997-2000 in South Korea.

¥ASMR: age-standardised mortality rate (per 100000 person-years).

$\S($ ASMR changes)/(ASMR in previous study period) $\times 100(\%)$

ISmoking-related causes: C33-34, J41-44 (ICD10) in Japan and C32-34, J40-44, J47 in South Korea.

ICD, International Statistical Classification of Diseases; NA, data not available.

Second, we had to apply a correction factor to take into account the varying proportions of men who were economically inactive during the census. Because mortality among the economically inactive was relatively high in Japan and South Korea, this had a large effect on the observed mortality patterns. However, the patterns observed in Japan and South Korea can already clearly be seen before the correction factor was applied (shown in online supplementary appendix figure 4-4).

Third, the data design in Japan and South Korea was cross-sectional unlinked, whereas that in European countries was longitudinal. A study comparing educational inequalities in mortality between a cross-sectional unlinked and a longitudinal design, showed that in the former design mortality rates among the high educated were underestimated, and mortality rates among the lower educated were overestimated. ${ }^{30}$ If similar differences would apply to mortality by occupational class, this would imply that in reality mortality among upper non-manual groups in Japan and South Korea are even higher, and that among manual groups even lower, than our results suggest.
Lastly, we focused on male mortality inequities in our analysis, because data on occupational class of women were often lacking. Future studies may exploit the strong increase of female workforce participation to investigate whether the patterns observed for men also apply to women.

\section{Interpretation}

It is highly remarkable that the social gradient observed in all European countries, with manual workers consistently having the highest mortality and upper non-manual workers having the lowest mortality, ${ }^{10-12} 22-24$ is currently not found in Japan and South Korea. In addition, we also find very high mortality among farmers and extremely low mortality among manual workers in Japan and South Korea. Previous studies have identified some but not all of these patterns. ${ }^{13} 1431$

These patterns of mortality in Japan and South Korea emerged only recently, due to an increase of mortality among upper non-manual workers and a continuing decline among manual 


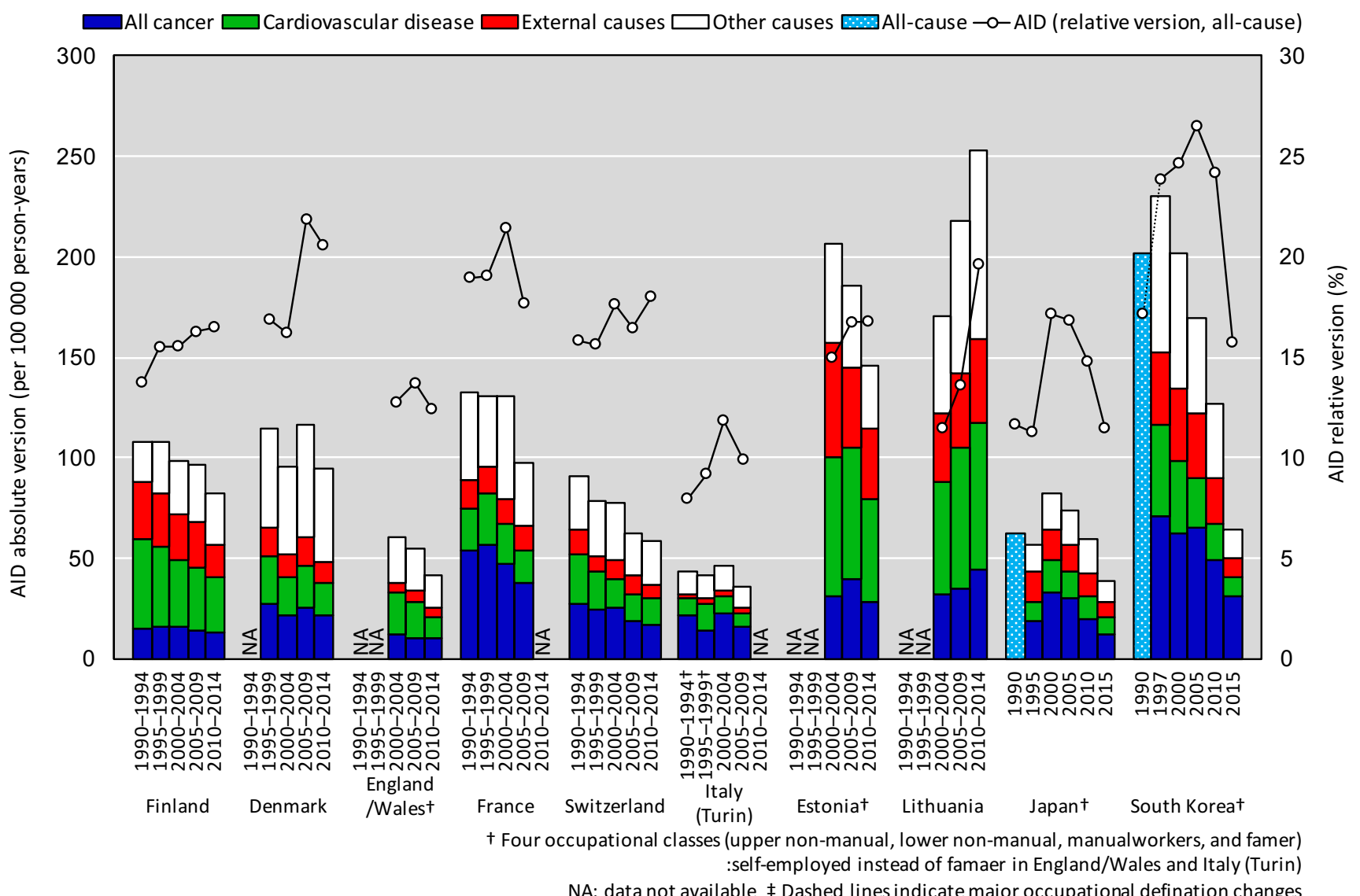

Figure 3 Changes in absolute and relative mortality inequalities (average inter-group difference: AID absolute and relative version), NA; data not available.

workers. Although both countries experienced an increase, although it with a different timing, the increase (both absolute and relative term) observed in Japan was almost twice as large as that observed in South Korea. Other studies have shown that although South Korea also experienced the 1997 Asian financial economic crisis, the negative effect on mortality was limited. ${ }^{32}$ Meanwhile, despite the 2008 global financial crisis unfavourable mortality changes were not observed in European countries except in Lithuania. ${ }^{33}$

A possible mechanism underlying the rising mortality of upper non-manual workers is a change in their social work environment after the economic crises in Japan and South Korea. Japan's economy underwent a long recession after the early 1990s, and the Japanese labour market changed as a result of 'organisational streamlining and downsizing' which caused an increase in working hours, particularly among men. ${ }^{34}$ Japanese managers have often been described as 'playing managers', because in this process they lost decision-making discretion while encountering ever greater psychological demands. ${ }^{35}$ It is suspected that similar unfavourable changes occurred in South Korea after the 2008 global financial crisis, as a result of increased psychological stress and job insecurity due to corporate downsizing and market restructuring. Whereas overtime hours of most other workers are decreasing due to social demands to reduce working hours, the work burden of managers has been increasing. Together with culture-specific responses to increased stress, such as feelings of shame, this may explain the increasing suicide mortality rates among upper non-manual workers in Japan and South Korea. ${ }^{3637}$
However, it seems that other factors explain rising cancer mortality. Previous studies have suggested that Japanese managers and professional workers may not find the time for health check-ups due to their long working hours and heavy job demands, and therefore have high mortality from cancer. ${ }^{13}{ }^{14}$ However, we could not find any statistics showing less health service utilisation among Japanese managers and professional workers. In any case, further study is needed to disclose why upper non-manual workers, who generally have more material (eg, income) and non-material (eg, social support or social participation) resources to cope with psychological and physical stress, were so vulnerable during the economic crisis in Japan and South Korea.

One possible explanation for the mortality patterns in Japan and South Korea is inconsistent and/or small differences between occupational groups in proximal risk factors for mortality. Several studies have shown upper class workers in Japan to have a relatively high prevalence of physical inactivity, high blood pressure and obesity. ${ }^{3-40}$ One study also found inequality in smoking prevalence among Japanese workers to be smaller than in other high-income countries. ${ }^{41}$ In South Korea, inequalities in unfavourable health behaviours and other proximal risk factors by occupational class were smaller than those by educational level. ${ }^{42}$ Another possible explanation is that the composition of occupational classes is different between Japan and South Korea and European countries. The group of manual workers consisted of over $20 \%$ of men with a high educational background (defined as International Standard Classification of Education 5 and 6) in Japan and South Korea, whereas the 
proportions were $10 \%$ or less in European countries (shown in online supplementary appendix table 2-2). This may have contributed to lower mortality among manual workers in Japan and South Korea, because level of education is a strong and consistent determinant of mortality in South Korea (unfortunately, there is little evidence on educational inequalities in mortality in Japan, due to a lack of educational information in Japanese vital statistics records). ${ }^{18}$

Previous studies have offered various other explanations for the patterns of health inequalities in Japan and South Korea. It has been suggested that Japan has smaller inequalities in mortality because of its smaller income inequalities and higher levels of social cohesion. ${ }^{43}$ However, according to OECD statistics, Japan does not really have smaller income inequalities than most European countries. ${ }^{44}$ Japan and South Korea also have

\section{What is already known on this topic}

- Inequalities in mortality and morbidity by socioeconomic position usually form steep and persistent gradients, but it is unclear whether this also applies to Japan and South Korea, two countries which have been recognised as global life expectancy leaders.

- Health inequalities in Japan and South Korea have sometimes been reported to be unique, with some studies reporting rising mortality among managers and professionals after the late 1990s in Japan and after the late 2000s in South Korea.

- However, this picture has remained uncertain due to a lack of direct comparisons to other high-income countries.

\section{What this study adds}

- In the most recent time period, male mortality was consistently higher in the manual group in eight European countries, but not in Japan and South Korea.

- The recently observed patterns in Japan and South Korea emerged during the last 25 years, as a result of rising mortality from cancer and external causes (particularly suicide) among the upper non-manual group, whereas mortality declined strongly among lower non-manual and manual groups.

- The timing of the mortality changes among the upper nonmanual group in Japan and South Korea suggests that these were due to the economic crisis of the late 1990s (in Japan) and late 2000s (in South Korea).

\section{Policy implications}

- Japan has comparatively small mortality inequalities both in absolute and relative terms, whereas South Korea has been rapidly catching up with European countries and Japan due to strong mortality declines among lower non-manual and manual worker groups.

- The mortality inequality changes experienced in Japan and South Korea serve as a reminder that high socioeconomic position, which generally provides more material and nonmaterial resources to cope with physical and psychological stress, does not guarantee better health, and that high mortality rates among skilled/unskilled manual worker groups are not inevitable. different disease structures: as we have seen above, the contribution of specific diseases to mortality inequalities in Japan ${ }^{14}$ and South Korea ${ }^{45}$ is different from what we observe in other high-income countries. ${ }^{10-12}$ The larger share of cancer, for which socioeconomic inequalities in mortality tend to be smaller than for cardiovascular disease, may therefore contribute to smaller inequalities in all-cause mortality in Japan and South Korea.

There are also important differences in welfare policy and labour protection regulations between European countries and Japan and South Korea. ${ }^{46} 47$ The 'welfare regime' of Japan and South Korea has been characterised as 'Confucian', because of its greater emphasis on the role of the family and a stricter work ethic. $^{48}$ For example, society is rather tolerant of overtime work, and moreover, managers often do unpaid overtime work in Japan and South Korea. ${ }^{47}$ It is possible that these differences have contributed to the differences in the health effects of economic crises on upper non-manual workers.

\section{CONCLUSIONS}

Patterns of mortality by occupational class are remarkably different between European countries and Japan and South Korea. The recently observed patterns in the latter two countries call into question the often assumed universality of the relationship between socioeconomic position and health, and indicate that national context may act as an important modifier of this relationship. Further study of factors contributing to very low mortality among manual workers, and comparatively high mortality of upper non-manual workers, in Japan and South Korea, is necessary to shed more light on the explanation of these remarkable findings.

\section{Author affiliations}

${ }^{1}$ Department of Public Health, Erasmus University Medical Center, Rotterdam, The Netherlands

${ }^{2}$ Department of Public Health, Graduate School of Medicine, The University of Tokyo, Tokyo, Japan

${ }^{3}$ Epidemiology, Biostatistics and Prevention Institute, University of Zürich, Zürich, Switzerland

${ }^{4}$ Department of Public Health, University of Copenhagen, Copenhagen, Denmark ${ }^{5}$ Department of Health Management, Lithuanian University of Health Sciences, Kaunas, Lithuania

${ }^{6}$ Stockholm Centre for Health and Social Change, Södetörn University, Huddinge, Sweden

${ }^{7}$ Department of Epidemiology and Biostatistics, National Institute for Health Development, Tallinn, Estonia

${ }^{8}$ Population Research Unit, Department of Social Reseach, University of Helsinki, Helsinki, Finland

${ }^{9}$ INSERM, Institut Pierre Louis d'Epidémiologie et de Santé Publique, Sorbonne Universités, Paris, France

Correction notice This article has been corrected since it first published. Figures 1,2 and 3 have been increased in size to aid readability.

Acknowledgements The authors thank the support of Chiara Di Girolamo (Department of Medical and Surgical Sciences, Alma Mater Studiorum, University of Bologna) with regard to data accuracy.

Contributors HT had full access to all the study data and was responsible for data integrity, the accuracy of the data analysis, and drafting the manuscript. HT and JPM contributed to the concept and design of the study. HT and YK acquired the data in Japan and HT harmonised the data. WJN and JPM acquired the data in European countries except for France and WJN harmonised the data. GM acquired the data in France and harmonised the data. MB, HB-H, RK, ML and PM contributed to acquire the data in European countries. JSL acquired the data in South Korea and HT harmonised the data. HT, WJN and JPM were responsible for data analysis and interpretation, while $\mathrm{HT}$ conducted the statistical analysis. All authors critically reviewed the manuscript. YK and JPM also supervised the study and provided administrative, technical, and material support.

Funding This work was supported by the following funding. HT received the Japan Public-Private Partnership Student Study Abroad Program (Tobitate! Study Abroad Initiative) funding [S171N126010017] to study at Erasmus MC. This study was conducted as part of the LIFEPATH project, which has received financial support from 
European Commission Horizon 2020 Grant [633666]. Data were partly collected as part of the Developing Methodologies to Reduce Inequalities in the Determinants of Health (DEMETRIQ) project, which received support from European Commission Grant [FP7-CP-FP 278511]. The funder had no role in the design and conduct of the study; collection, management, analysis and interpretation of the data; preparation, review or approval of the manuscript; and decision to submit the manuscript for publication.

\section{Competing interests None declared.}

Patient consent for publication Not required.

Provenance and peer review Not commissioned; externally peer reviewed.

Data sharing statement All data relevant to the study are included in the article or uploaded as supplementary information.

Open access This is an open access article distributed in accordance with the Creative Commons Attribution 4.0 Unported (CC BY 4.0) license, which permits others to copy, redistribute, remix, transform and build upon this work for any purpose, provided the original work is properly cited, a link to the licence is given, and indication of whether changes were made. See: https://creativecommons.org/ licenses/by/4.0/.

\section{REFERENCES}

1 Marmot M. Social determinants of health inequalities. Lancet 2005:365:1099-104.

2 Deaton A. Policy implications of the gradient of health and wealth. Health Aff 2002:21:13-30.

3 Mackenbach JP, Bopp M, Deboosere P, et al. Determinants of the magnitude of socioeconomic inequalities in mortality: a study of 17 European countries. Health Place 2017;47:44-53.

4 Vaupel JW, Zhang Z, van Raalte AA. Life expectancy and disparity: an international comparison of life table data. BMJ Open 2011;1:e000128.

5 Kontis V, Bennett JE, Mathers CD, et al. Future life expectancy in 35 industrialised countries: projections with a Bayesian model ensemble. The Lancet 2017;389:1323-35.

6 Kagamimori S, Gaina A, Nasermoaddeli A. Socioeconomic status and health in the Japanese population. Soc Sci Med 2009;68:2152-60.

7 Martikainen $\mathrm{P}$, Lahelma $\mathrm{E}$, Marmot $\mathrm{M}$, et al. A comparison of socioeconomic differences in physical functioning and perceived health among male and female employees in Britain, Finland and Japan. Soc Sci Med 2004;59:1287-95.

8 Martikainen P, Ishizaki M, Marmot MG, et al. Socioeconomic differences in behavioural and biological risk factors: a comparison of a Japanese and an English cohort of employed men. Int J Epidemiol 2001;30:833-8.

9 Khang Y-H, Lee S-il. Health inequalities policy in Korea: current status and future challenges. J Korean Med Sci 2012;27 Suppl:S33-40.

10 Mackenbach JP, Kulhánová I, Artnik B, et al. Changes in mortality inequalities over two decades: register based study of European countries. BMJ 2016;353.

11 Mackenbach JP, Stirbu I, Roskam A-JR, et al. Socioeconomic inequalities in health in 22 European countries. N Engl J Med 2008:358:2468-81.

12 Mackenbach JP, Bos V, Andersen 0, et al. Widening socioeconomic inequalities in mortality in six western European countries. Int J Epidemiol 2003;32:830-7.

13 Wada K, Kondo N, Gilmour S, et al. Trends in cause specific mortality across occupations in Japanese men of working age during period of economic stagnation, 1980-2005: retrospective cohort study. BMJ 2012;344:e1191.

14 Tanaka H, Toyokawa S, Tamiya N, et al. Changes in mortality inequalities across occupations in Japan: a national register based study of absolute and relative measures, 1980-2010. BMJ Open 2017;7:e015764.

15 Chan $\mathrm{CH}$, Caine ED, You S, et al. Suicide rates among working-age adults in South Korea before and after the 2008 economic crisis. J Epidemiol Community Health 2014:68:246-52.

16 Marinacci C, Grippo F, Pappagallo M, et al. Social inequalities in total and causespecific mortality of a sample of the Italian population, from 1999 to 2007. Eur J Public Health 2013;23:582-7.

17 Federico B, Mackenbach JP, Eikemo TA, et al. Educational inequalities in mortality in northern, mid and southern Italy and the contribution of smoking. J Epidemiol Community Health 2013;67:603-9.

18 Khang Y-H, Lynch JW, Kaplan GA. Health inequalities in Korea: age- and sexspecific educational differences in the 10 leading causes of death. Int J Epidemiol 2004:33:299-308

19 Erikson R, Goldthorpe JH, Portocarero L. Intergenerational class mobility and the convergence thesis: England, France and Sweden. Br J Sociol 1979:30:415-41.

20 Ishida $\mathrm{H}$. Industrialization, class structure, and social mobility in postwar Japan. $\mathrm{Br} J$ Sociol 2001;52:579-604

21 Takenoshita $\mathrm{H}$. Intergenerational mobility in East Asian countries: a comparative study of Japan, Korea and China. Int J Jpn Sociol 2007;16:64-79.
22 Kunst AE, Groenhof F, Mackenbach JP. Mortality by occupational class among men 3064 years in 11 European countries. EU Working Group on socioeconomic inequalities in health. Soc Sci Med 1998;46:1459-76.

23 Kunst AE, Groenhof F, Mackenbach JP, et al. Occupational class and cause specific mortality in middle aged men in 11 European countries: comparison of population based studies. EU Working Group on socioeconomic inequalities in health. BMJ 1998;316:1636-42.

24 Toch-Marquardt M, Menvielle G, Eikemo TA, et al. Occupational class inequalities in all-cause and cause-specific mortality among middle-aged men in 14 European populations during the early 2000s. PLoS One 2014;9:e108072.

25 Shkolnikov VM, Andreev EM, Jdanov DA, et al. Increasing absolute mortality disparities by education in Finland, Norway and Sweden, 1971-2000. J Epidemiol Community Health 2012;66:372-8.

26 Mackenbach JP, Kunst AE. Measuring the magnitude of socio-economic inequalities in health: an overview of available measures illustrated with two examples from Europe. Soc Sci Med 1997;44:757-71.

27 Harper S, Lynch J, Meersman SC, et al. An overview of methods for monitoring social disparities in cancer with an example using trends in lung cancer incidence by area-socioeconomic position and race-ethnicity, 1992-2004. Am J Epidemiol 2008;167:889-99.

28 Moser K, Shkolnikov V, Leon DA. World mortality 1950-2000: divergence replaces convergence from the late 1980s. Bull World Health Organ 2005;83:202-9.

29 Wagstaff A, Paci P, van Doorslaer E. On the measurement of inequalities in health. Soc Sci Med 1991;33:545-57.

30 Shkolnikov VM, Jasilionis D, Andreev EM, et al. Linked versus unlinked estimates of mortality and length of life by education and marital status: evidence from the first record linkage study in Lithuania. Soc Sci Med 2007;64:1392-406.

31 Lee H-E, Kim H-R, Chung YK, et al. Mortality rates by occupation in Korea: a nationwide, 13-year follow-up study. Occup Environ Med 2016;73:329-35.

32 Khang Y-H, Lynch JW, Kaplan GA. Impact of economic crisis on cause-specific mortality in South Korea. Int J Epidemiol 2005;34:1291-301.

33 Mackenbach JP, Valverde JR, Artnik B, et al. Trends in health inequalities in 27 European countries. Proc Natl Acad Sci U S A 2018;115:6440-5.

34 Genda Y, Kuroda S, Ohta S. Does downsizing take a Toll on retained staff? An analysis of increased working hours in the early 2000s in Japan. J Jpn Int Econ 2015:36:1-24.

35 Kondo N, Oh J. Suicide and karoshi (death from overwork) during the recent economic crises in Japan: the impacts, mechanisms and political responses. J Epidemio Community Health 2010;64:649-50.

36 Jeon SY, Reither EN, Masters RK. A population-based analysis of increasing rates of suicide mortality in Japan and South Korea, 1985-2010. BMC Public Health 2016;16.

37 Chang S-S, Gunnell D, Sterne JAC, et al. Was the economic crisis 1997-1998 responsible for rising suicide rates in East/Southeast Asia? A time-trend analysis for Japan, Hong Kong, South Korea, Taiwan, Singapore and Thailand. Soc Sci Med 2009:68:1322-31.

38 Takao S, Kawakami N, Ohtsu T, et al. Occupational class and physical activity among Japanese employees. Soc Sci Med 2003;57:2281-9.

39 Takashima Y, Yoshida M, Kokaze A, et al. Relationship of occupation to blood pressure among middle-aged Japanese men--the significance of the differences in body mass index and alcohol consumption. J Epidemiol 1998;8:216-26.

40 Morikawa Y, Tabata M, Kido T, et al. Occupational class inequalities in behavioral and biological risk factors for cardiovascular disease among workers in medium- and small-scale enterprises. Ind Health 2012;50:529-39.

41 Lahelma $\mathrm{E}$, Lallukka T, Laaksonen $\mathrm{M}$, et al. Social class differences in health behaviours among employees from Britain, Finland and Japan: the influence of psychosocial factors. Health Place 2010;16:61-70.

42 Khang Y-H, Lynch JW, Yang S, et al. The contribution of material, psychosocial, and behavioral factors in explaining educational and occupational mortality inequalities in a nationally representative sample of South Koreans: relative and absolute perspectives. Soc Sci Med 2009:68:858-66.

43 Ikeda N, Saito E, Kondo N, et al. What has made the population of Japan healthy? The Lancet 2011:378:1094-105.

44 Moatsos M, Baten J, Foldvari P, et al. Income inequality since 18202014

45 Jung-Choi K, Khang YH, Cho HJ. Changes in contribution of causes of death to socioeconomic mortality inequalities in Korean adults. J Prev Med Public Health 2011;44:249-59

46 Iwasaki K, Takahashi M, Nakata A. Health problems due to long working hours in Japan: working hours, workers' compensation (Karoshi), and preventive measures. Ind Health 2006:44:537-40.

47 Park J, Kim Y, Han B. Long working hours in Korea: based on the 2014 Korean working conditions survey. Saf Health Work 2017:8:343-6.

48 Bambra C. Going beyond the three worlds of welfare capitalism: regime theory and public health research. J Epidemio/ Community Health 2007;61:1098-102.

49 Aspalter C. The East Asian welfare model. Int J Soc Welf 2006;15:290-301.

50 Kanai A. "Karoshi (Work to Death)" in Japan. J Bus Ethics 2009;84:209-16. 